\title{
ДЕФИЦИТ ВИТАМИНА Д КАК ФАКТОР КАРДИОМЕТАБОЛИЧЕСКОГО РИСКА ВОЕННОСЛУЖАЩИХ В АРКТИКЕ
}

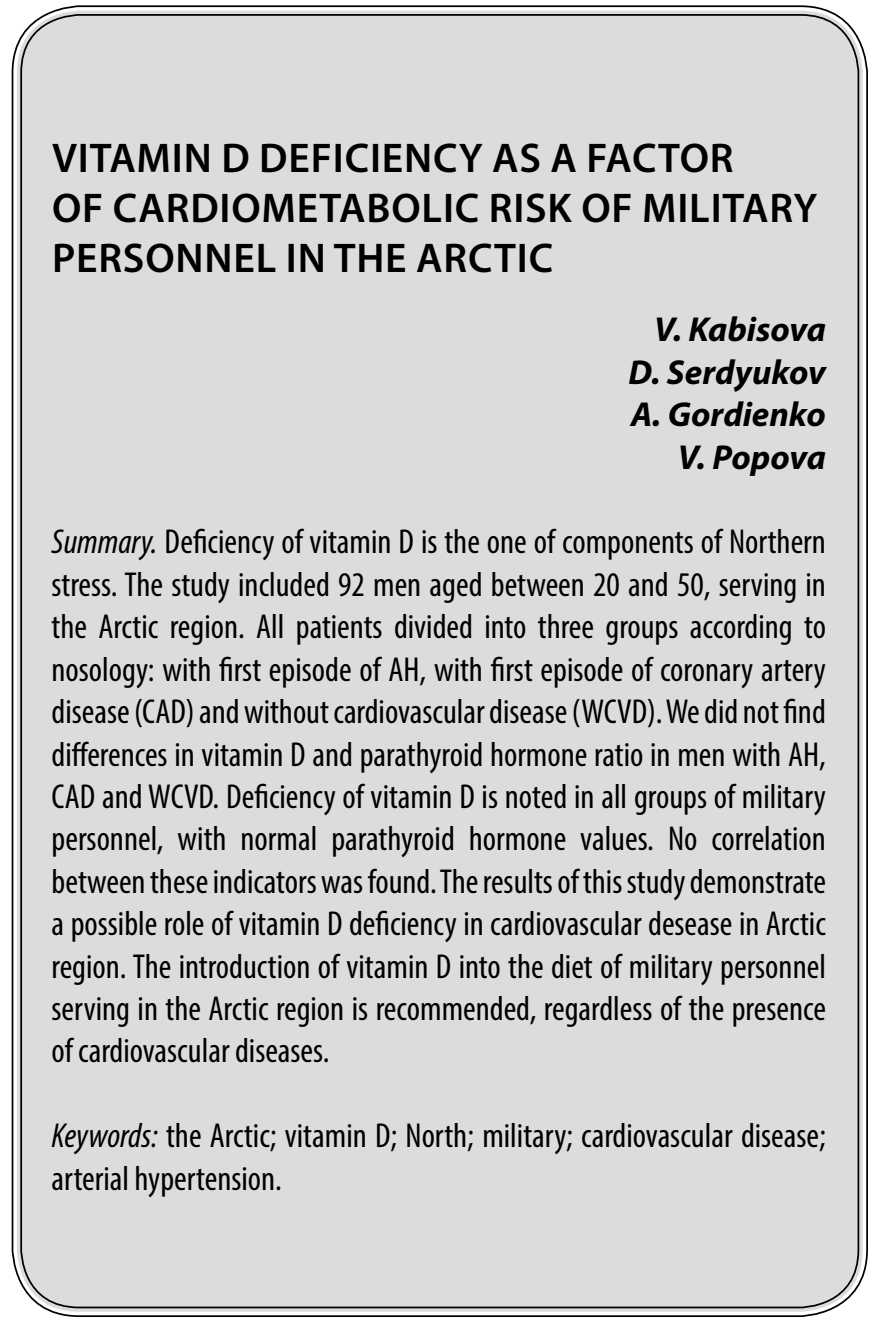

\section{Введение}

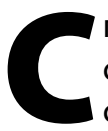

политико-стратегической, экономической и ресурсной точек зрения Арктический регион является одним из приоритетных, и требует обеспечения военной безопасности, защиты и охраны государственной границы Российской Федерации, тем самым приводя к расширению военных баз и количества военнослужащих [5].

Данная местность характеризуется суровыми климатическими условиями, вызывая многокомпонентное адаптационное воздействие, включая колебания атмосферного давления и электромагнитные флуктуации, низкую температуру и абсолютную влажность, фотопериодизм и изменения рациона питания, что при длительной
Кабисова Влада Игоревна

Аспирант, Военно-медицинская академия им. С. М. Кирова, г. Санкт-Петербург vladakabisova@gmail.com

Сердюков Дмитрий Юрьевич

Д.м.н., старший преподаватель, Военно-Медицинская академия им. С.М. Кирова, г. Санкт-Петербург

Гордиенко Александр Волеславович

Д.м.н., профессор, заслуженный врач Российской

Федерации, Военно-Медицинская академия им. С. М. Кирова, г. Санкт-Петербург

Попова Вероника Борисовна

К.м.н., дочент, Первый Санкт-Петербургский государственный медицинский университет им. акад. И.П. Павлова

Аннотация. Освещаются ключевые механизмы воздействия витамина Д на сердечно-сосудистую систему. Представлены результаты оценки концентрации витамина Д и паратиреоидного гормона у 92 военнослужащих на Севере, разделенных на 3 группы по нозологическому признаку: пациенты с дебютом ишемической болезни сердца, гипертонической болезни и без сердечно-сосудистых заболеваний. Статистически значимых межгрупповых различий по уровню витамина Д и паратгормона не выявлено. Отмечается выраженный дефицит витамина Д у всех групп военнослужащих, при нормальных значениях паратгормона. Корреляционной связи между данными показателями не выявлено. Рекомендовано введение препаратов витамина Д в рацион военнослужащих, проходящим службу в Арктическом регионе, вне зависимости от наличия сердечно-сосудистых заболеваний.

Ключевые слова: Арктика; витамин Д; Север; авитаминоз; военнослужащие; сердечно-сосудистые заболевания; артериальная гипертензия.

экспозиции (служба более 3 лет) рассматривается как действие арктического военно-профессионального фактора [2].

Сердечно-сосудистая заболеваемость и смертность занимают лидирующие позиции по всему миру с увеличением показателей по мере продвижения от экватора к высоким широтам [7].

Одним из компонентов синдрома полярного напряжения, оказывающим негативное действие на сердечно-сосудистую систему, является дефицит витамина Д [1]. Причиной гиповитаминоза служит как алиментарная недостаточность, вследствие несбалансированного питания военнослужащих в Арктике [4], так и снижение ультрафиолетового воздействия в период полярной 
ночи и холодного полярного дня, что блокирует образование витамина в коже. Еще одной особенностью дефицита жирорастворимых витаминов на Севере является повышенный их расход при запуске каскада перекисного окисления липидов. Выступая в роли универсального антиоксиданта, без зависимости от мембранных рецепторов, витамин Д нивелирует оксидативный стресс, оказывает сосудорасширяющее действие за счет увеличения метаболизма оксида азота, предотвращает отложение кальция в стенках сосудов, снижает провоспалительную активность и инсулинорезистентность [3].

\section{Цель исслемования}

Оценить уровень витамина Д в крови у военнослужащих молодого и среднего возраста, проходящих службу в Арктическом регионе, и проанализировать его влияние на сердечно-сосудистую заболеваемость.

\section{материалы и методы}

В исследование было включено 92 военнослужащих в возрасте от 20 до 50 лет, проходящих службу в Арктическом регионе, находящихся на лечении в кардиологическом отделении Военно-морского клинического госпиталя Северного флота в связи с впервые выявленным эпизодом сердечно-сосудистого заболевания в 2018 году. Все пациенты были разделены на три группы по нозологиям: с гипертонической болезнью (ГБ) - 43 человека, с ишемической болезнью сердца (ИБС) - 26 человек и без сердечно-сосудистых заболеваний (СС3) - 23 человека.

Критериями исключения из исследования являлись: инфаркт миокарда, инсульт, значимые нарушения ритма сердца и проводимости, сахарный диабет, гиперурикемия, вторичные артериальная гипертензия и семейные дислипопротеидемии, заболевания щитовидной железы, заболевания других органов и систем в фазе обострения.

В рамках обследования были выполнены сбор жалоб и анамнеза, выявлялись факторы риска сердечно-сосудистых заболеваний. Оценивались уровень витамина D (25-OH D), паратиреоидный гормон. Исследования концентраций в сыворотке крови витамина Д и паратгормона проводили на автоматическом анализаторе Architec 2000i [Abbott, США] с помощью хемилюминесцентного иммуноанализа на микрочастицах.

Интерпретация данных проводилась в соответствии с рекомендациями Российской Ассоциации Эндокринологов от 2016 года, на основе которых при концентрации 25(OH)D в крови менее 10 нг/мл определялся выраженный дефицит витамина D, менее 20 нг/мл - дефицит витамина D, от 20 до 30 нг/мл - недостаточность, $\geq 30$ нг/ мл - адекватные уровни содержания витамина в крови. Концентрация паратиреоидного гормона в диапазоне 15,0-68,0, пг/мл расценивалась как норма.

Статистическая обработка полученных данных производилась на базе персонального компьютера в табличном процессоре Excel 2013 и пакете прикладных программ SPSS Statistics 22,0.

При анализе количественных данных на первом этапе выполнялась оценка нормальности распределения изучаемых параметров с помощью критерия Шапиро-Уилка, равенство дисперсий проверялось критерием Ливиня (расчёт основан на медиане).

Размер выборок в некоторых случаях был небольшим (менее 30 случаев), распределение примерно в половине случаев отличалось от нормального, поэтому применён непараметрический инструментарий.

Для сравнения количественных и ранговых данных применялся критерий Краскела-Уоллиса, апостериорное сравнение проводилось с помощью критерия GT2-Гохберга при равенстве дисперсий и критерия Геймса-Хоуэлла при неравенстве. Описание данных и их дисперсии имело вид: Ме (Q25; Q75), где Ме - медиана, Q25 и Q75 25\% и 75\% квартили соответственно

Корреляционный анализ проводился с помощью о-критерия Пирсона.

Критический уровень значимости, при котором отвергалась нулевая гипотеза об отсутствии различий между изучаемыми группами, выбран $p=0,05$.

\section{Результаты}

При оценке содержания витамина Д в крови военнослужащих при статистической обработке не удалось выявить значимых различий между группами (Табл. 1). Концентрация 25(OH)D в 100\% случаев оказалась ниже адекватного уровня содержания витамина (<30 нг/мл) вне зависимости от наличия или отсутствия сердечно-сосудистого заболевания.

у 18\% пациентов с дебютом ГБ определялся выраженный дефицит витамина Д, у 76,8\% дефицит витамина Д, а у $5 \%$ недостаточность витамина Д. При этом в группе военнослужащих с впервые выявленной ИБС выраженный дефицит составил 11,5\%, дефицит - 69,2\%, недостаточность - 19,3\%, а в группе без СС3 15\%, 84\% и 1\% соответственно (Рис. 1).

Уровень паратиреоидного гормона находился в пределах нормы у всех военнослужащих, без значи- 
Таблица 1.

\begin{tabular}{|c|c|c|c|c|c|c|c|}
\hline \multirow{2}{*}{ Показатель } & \multicolumn{2}{|l|}{ ГБ } & \multicolumn{2}{|l|}{ ИБС } & \multicolumn{2}{|c|}{ Без CC3 } & \\
\hline & Me & (Q25; Q75) & Me & (Q25; Q75) & $\mathrm{Me}$ & (Q25; Q75) & \\
\hline \multirow{6}{*}{ Витамин Д } & \multirow{6}{*}{18,85} & \multirow{6}{*}{$(11,7 ; 26,63)$} & \multirow{6}{*}{14,05} & \multirow{6}{*}{$(11,03 ; 26,03)$} & \multirow{6}{*}{12,6} & \multirow{6}{*}{$(9,18 ; 15,05)$} & Краскелл-Уоллис \\
\hline & & & & & & & $p=0,157$ \\
\hline & & & & & & & Значимость \\
\hline & & & & & & & $P_{1-2}=0,719$ \\
\hline & & & & & & & $P_{1-3}=0,148$ \\
\hline & & & & & & & $P_{2-3}=0,394$ \\
\hline \multirow{6}{*}{$\begin{array}{l}\text { Парат } \\
\text { горомон }\end{array}$} & \multirow{6}{*}{50,95} & \multirow{6}{*}{$(44,13 ; 56,88)$} & \multirow{6}{*}{43,3} & \multirow{6}{*}{$(35,68 ; 56,83)$} & \multirow{6}{*}{33,7} & \multirow{6}{*}{$(23,55 ; 48,15)$} & Краскелл-Уоллис \\
\hline & & & & & & & $p=0,088$ \\
\hline & & & & & & & Значимость \\
\hline & & & & & & & $P_{1-2}=0,871$ \\
\hline & & & & & & & $P_{1-3}=0,107$ \\
\hline & & & & & & & $P_{2-3}=0,169$ \\
\hline
\end{tabular}

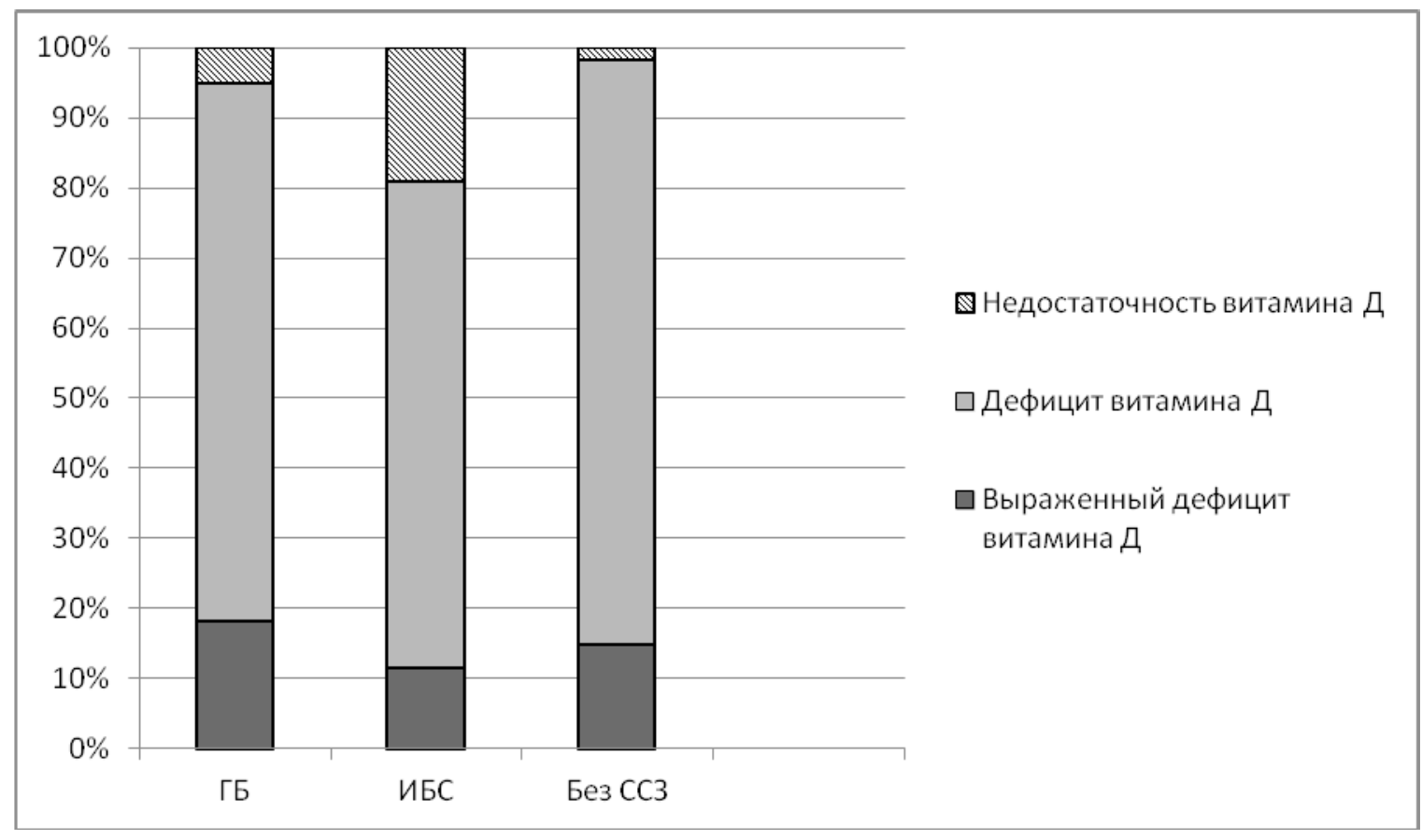

Pис. 1

мых межгрупповых различий. Взаимосвязи между концентрациями паратиреоидного гормона и витамина Д не выявлено ( $r=0,025$ при р 0,89).

\section{Обсужкение}

Несмотря на отсутствие значимых отличий концентрации витамина Д между группами, низкие его значения можно расценивать как неблагоприятный фактор службы в Арктическом регионе. Полученные данные согласуются с результатами исследования, проведенного сотрудниками кафедры факультетской терапии
Военно-медицинской академии им. С.М., согласно которому у военнослужащих на Севере уровень витамина Д достоверно ниже, по сравнению с военнослужащими Северо-Западного региона. При этом дефицит наблюдался у 96,5\%, а недостаточность у 3,4\% человек [8]. Служба в экстремальных климатогеографических условиях сопряжена с повышенным использованием жирорастворимых витаминов, сочетающейся с низкой инсоляцией и недостаточным поступлением витаминов с пищей [6]. Вероятно, длительно-продолжающийся дефицит со временем может приводить к истощению компенсаторных механизмов и состав- 
лять дополнительное звено в многофакторной цепочке, вызывающей сердечно-сосудистые заболевания на Севере.

Согласно метаанализу крупных рандомизированных международных исследований, не удалось выявить взаимосвязь между приемом препаратов витамина Д и снижением неблагоприятных кардиоваскулярных событий и сердечно-сосудистой смертности[9].

Но ни в одном из учтенных исследований не производилась оценка гипоавитаминоза Д в качестве триггера запуска сердечно-сосудистого континуума в комбинации с другими факторами риска, особенно в высоких широтах. Возраст включения пациентов в исследования варьировался от 50 до 60 лет в зависимости от половой принадлежности, что также исключает возможность донозологической профилактики в молодом и среднем возрасте.

Дефицит витамина Д может приводить к вторичному гиперпаратиреозу, повышая всасывание кальция в кишечнике. У всех военнослужащих уровень паратиреоидного гормона был в пределах нормы.

\section{Зак^ючение}

Гипоавитаминоз Д является междисциплинарной проблемой, находящий свое отражение как в кардиологии, так и в эндокринологии, травматологии и терапии.

Учитывая выраженный дефицит уровня витамина Д у военнослужащих молодого и среднего возраста, проходящих службу в зоне Крайнего севера, отсутствие нормальных значений данного показателя в 100\% случаев вне зависимости от наличия сердечно-сосудистого заболевания, распространенность рецепторов к витамину Д и его активное участие в метаболических процессах организма, целесообразно ввести профилактический прием данного препарата в рацион военнослужащих данного региона.

В качестве альтернативы капсульным формам или растворам, необходимо рассмотреть механизм обогащения витаминами общих продуктов питания, содержащих жир (такие как масло или молоко). Полученные данные свидетельствуют об эффективности применения специально созданных продуктов питания для целей коррекции витаминного статуса.

\section{ЛИТЕРАТУРА}

1. Андриянов А.И., Кириченко Н. Н., Субботина Т. И., Ивченко Е. В., Кравченко Е. В., Сметанин А. Л., Лазаренко Л. П. Витаминный статус военнослужащих и его коррекция // Вестник Российской военно-медицинской академии. 2016. № 3 (55). С. 239-244.

2. Гордиенко А.В., Сердюков Д. Ю. Ранняя диагностика и профилактика атеросклероза и факторов сердечно-сосудистого риска у военнослужащих-мужчин в условиях Арктической зоны и умеренных широт // Методические рекомендации. М.: Изд-во ВМедА. 2019. С. 32.

3. Колесников А.Н., Дубовая А. В., Удовитченко Ю. В. Участие витамина D в патогенезе заболеваний сердечно-сосудистой системы // Рос вестн перинатол и педиатр. 2018. № 63 (5). С. 43-50.

4. Кривцов А.В., Кириченко Н. Н., Ивченко Е. В., Сметанин А. Л., Андриянов А. И., Сороколетова Е. Ф., Кравченко Е. В., Коновалова И.А Физиолого-гигиеническая характеристика питания и водоснабжения воинского гарнизона в Арктике // Вестн. Росс. воен.-мед. акад. 2015. № 4 (52). С. $165-168$.

5. 0 сухопутных территориях Арктической зоны Российской Федерации: Указ Президента Российской Федерации от 2 мая 2014 года № 296

6. Потолицына Н.Н., Есева Т. В., Лаптева Н. К., Бойко Е. Р. Оценка витаминного статуса и способы его коррекции у военнослужащих на европейском севере // Вестник образования и развития науки Российской академии естественных наук. 2017. № 1. С. 122-130.

7. Солонин, Ю.Г., Бойко Е. Р. Медико-физиологические аспекты жизнедеятельности в Арктике // Арктика: экология и экономика. 2015. № 1. С. 70-75.

8. Тыренко В.В., Аганов Д. С., Топорков М. М., Цыган Е. Н., Бологов С. Г. Ранняя диагностика нарушения минерального обмена, как способ первичной и вторичной профилактики переломов у военнослужащих арктической группировки войск // Вестник Российской военно-медицинской академии. 2018. № 4 (64). C. 45-51.

9. Barbarawi M., Kheiri B., Zayed Y., Barbarawi 0., Dhillon H., Swaid B. D Supplementation and Cardiovascular Disease Risks in more than 83000 individuals in 21 randomized clinical trials. A Meta-analysis // JAMA Cardiol. 2019. Vol. 4. Suppl. 8. P. 765-776. D01:10.1001/jamacardio.2019.1870.

( Кабисова Влада Игоревна ( vladakabisova@gmail.com ), Сердюков Дмитрий Юрьевич,

Гордиенко Александр Волеславович, Попова Вероника Борисовна.

Журнал «Современная наука: актуальные проблемы теории и практики» 